\title{
Performance analysis of hybrid photovoltaic/wind energy system using KY boost converter
}

\author{
M. Pushpavalli ${ }^{1}$, N. M Jothi Swaroopan ${ }^{2}$ \\ ${ }^{1}$ Department of EEE, Sathyabama Institute of Science and Technology, India \\ ${ }^{2}$ Department of EEE, RMK Engineering College, India
}

\begin{tabular}{l}
\hline Article Info \\
\hline Article history: \\
Received Jul 3, 2018 \\
Revised Nov 17, 2018 \\
Accepted Dec 10, 2018 \\
\hline
\end{tabular}

Keywords:

Hybrid system

KY boost converter

MPPT tracking

\begin{abstract}
Nowadays tremendous increase in renewable energy technologies available in abounding nature energy extracted from sun, wind etc. This Proposed topology gathered maximum power using multi input ky boost converters for hybrid energy. This hybrid topology operates mainly delivered the power from renewable energy sources solar/wind to dc bus. In the absence of any one source, wind or solar supplies power to the dc bus. Without any renewable energy sources battery deliver the power to dc bus.An inverter type module convert the power from dc bus to ac grid. In this paper effectiveness of hybrid renewable energy is simulated through MATLAB/SIMULINK.
\end{abstract}

Copyright (C) 2019 Institute of Advanced Engineering and Science. All rights reserved.

\section{Corresponding Author:}

M. Pushpavalli, Department of EEE,

Sathyabama Institute of Science and Technology,

Chennai, India.

Email: pushpa_10479@rediffmail.com

\section{INTRODUCTION}

The mankind faces the important challenges in the 21 st century are constructing the power planet, reducing the carbon emissions and reducing the cost of energy. The main solutions for the above problems are invention of new energy supplies and other one is renewable energy. It can reduce the cost of generation. The major renewable energy sources are solar and winds abundantly available in nature so tapping these sources are feasible with energy storage unit [1]-[3]. The innovations in hybrid power promise to enhance efficiencies across the globe. The integration of solar and wind are confined to new innovation with battery backup system [4]. There are three common methods to integrate the renewable energy systems are dc bus coupling, ac bus coupling and hybrid coupling [5]. The intelligent control techniques are fuzzy logic control, anfis control, genetic algorithm and neural network are trained to extract maximum power from hybrid system. The system size, control techniques and optimum power flow are incorporated with different approaches. Converter and inverters are mainly play role for selection in hybrid energy system with an efficient energy dispatch [6], [7]. This paper mainly focused, a ky boost converter topology for hybriding the renewable energy sources using wind and sun have been implemented. The main problem is unpredicted nature if any one of the source is available other alternative source can give the uninterrupted output. If both the sources are unavailable the storage unit has to meet out the demand. The characteristics of ky boost converter have capability to eliminate the harmonics, increased stability, continuous inductor current. It has been proved that ky converter has more efficient operation than boost converter [8].

The proposed hybrid system have solar and wind as renewable power sources, ky boost converter, battery and grid. To balance the power flow among all these sources power flow management system is important [9]. Surplus power from the renewable energy used to charging the battery. If power generated is 
more than a demand bidirectional converter connected to storage system which in turn connected to grid. If power demand is greater than renewable energy power generated, then battery absorb the power [10]. Hence the power can flow from battery to grid or vice versa so bidirectional converters are used. Without any interruption, power should flow to grid. The grid-connected hybrid solar-wind-battery-based system as shown in Figure 1.

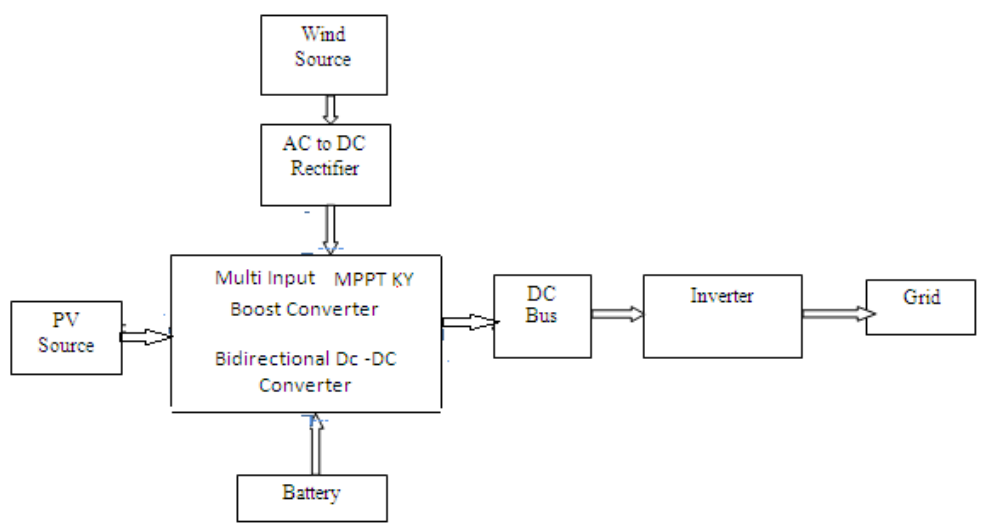

Figure 1. Hybrid photovoltaic/wind energy system using ky boost converter

\section{PV SYSTEM}

The equivalent circuit diagram of PV module consisting of an ideal current source with one diode in parallel with the consisting of two resistors, series resistor Rs and parallel resistor Rp as shown in Figure 2. A simple photovoltaic model extracts the electrical energy from solar energy [11]. The electric power produced by PV system is a result a PV output voltage (V) and PV output current (I) by (1) and (2).

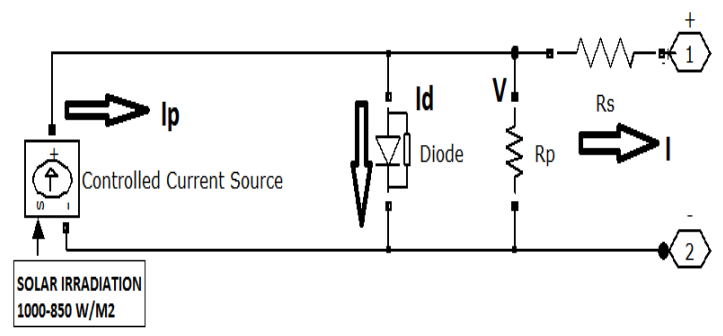

Figure 2. Equivalent circuit diagram of pv model

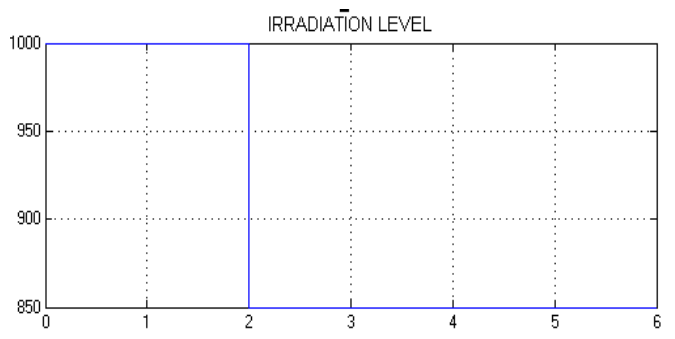

Figure 3. irradiation level

$$
\begin{aligned}
& \mathrm{I}=\mathrm{Ip}-\mathrm{Io}(\mathrm{e}(\mathrm{v}+\mathrm{I} \mathrm{Rs} / \mathrm{nVT})-1)+\mathrm{V} / \mathrm{Rp} \\
& \mathrm{V}=\mathrm{Vd}-\mathrm{I} \text { Rs }
\end{aligned}
$$

The temperature and irradiance level mainly contribute to open circuit voltage (Voc) and short circuit current (Isc) by (3) and (4).

$$
\begin{aligned}
& \text { Isc }=(\mathrm{Isc}, \mathrm{n}+\alpha \mathrm{I} \Delta \mathrm{T})^{*} \text { Insolation/Standard Insolation } \\
& \mathrm{Voc}=(\mathrm{Voc}, \mathrm{n}+\alpha \mathrm{V} \Delta \mathrm{T}))^{*} \text { Insolation/Standard Insolation }
\end{aligned}
$$

Voc,n and Isc,n are open circuit voltage and the short-circuit current of PV module respectively under, Standard temperature $=25 \mathrm{C}$ and Standard Insolation $=1 \mathrm{KW} / \mathrm{m} 2 . \Delta \mathrm{T}$ is the temperature change. $\alpha \mathrm{V}$ is the temperature coefficient of Voc and $\alpha \mathrm{I}$ is the temperature coefficient of Isc.

Maximum PV panel power generation varies from 4300 watts at irradiance $1000 \mathrm{w} / \mathrm{m} 2$ and 3750 
watts at irradiance $850 \mathrm{w} / \mathrm{m} 2$ shown in Figures 3 and 4 . By connecting the parallel and series combination of $\mathrm{PV}$ panel, the I-V and P-V characteristics showed in Figures 5 and 6 . By using arrays combination the maximum output voltage $=270$ volt $(54 * 5)$. The PV panel maintains the constant $\mathrm{DC}$ voltage $(270$ volt $)$ shown in Figure 7. PV module specifications as shown in Table 1.

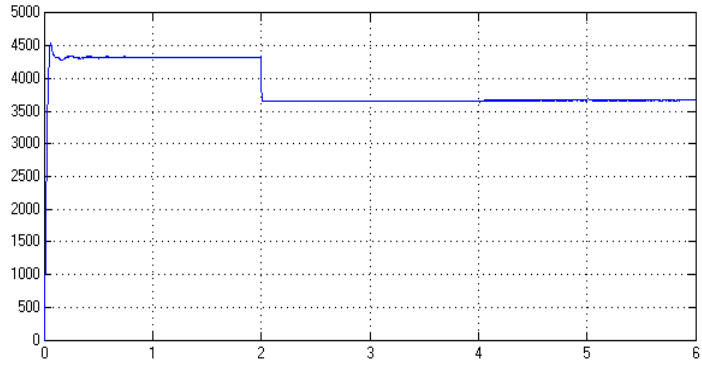

Figure 4. PV panel power

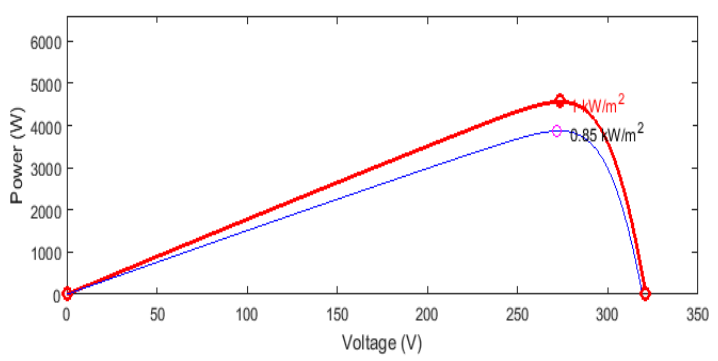

Figure 6. P-V characteristics of PV array

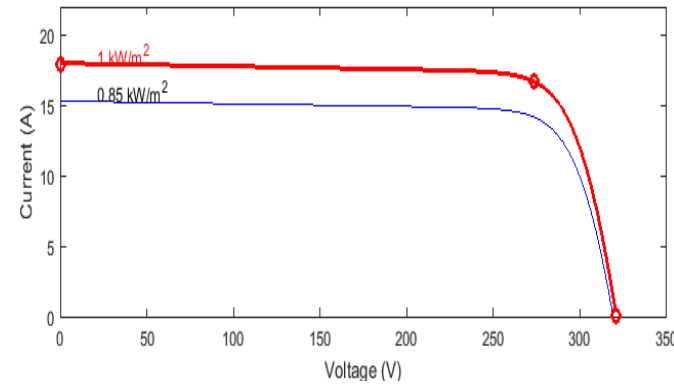

Figure 5. I-V characteristics of PV array

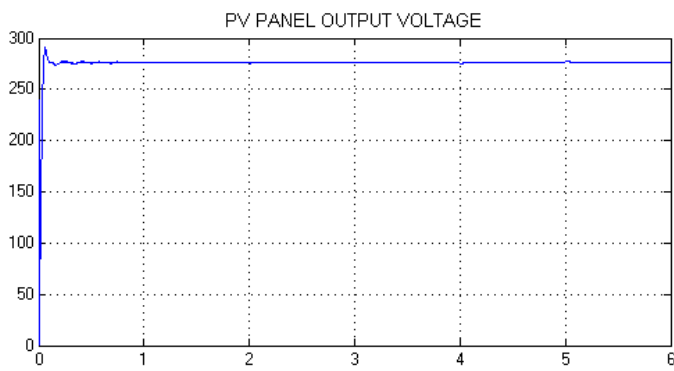

Figure 7. PV panel output voltage-270 volt

Table 1. PV module specifications

\begin{tabular}{lc}
\hline Spesifications & Value \\
\hline Open circuit Voltage & $64.2 \mathrm{~V}$ \\
Short circuit current & $5.96 \mathrm{~A}$ \\
Voltage at maximum power point & $54 \mathrm{~V}$ \\
Current at maximum power point & $5.96 \mathrm{~A}$ \\
Cells per module & 96 \\
Parallel Strings \& Series connected & $3 \& 5$ \\
modules per string & \\
\hline
\end{tabular}

\section{SYSTEM ARCHITECTURE OF PV SYSTEM/WIND SYSTEM WITH MULTI INPUT KY BOOST CONVERTER}

The main part of the proposed system is the multi-input ky boost dc-dc converter that be linked two renewable energy sources. DC-DC ky boost converter connected between energy sources and the dc bus. Multi input ky boost converter system architecture of a solar array system/wind system is shown in Figure 8. The maximum power point (MPP) tracking of both the renewable energy sources, accomplished with two controllable switches. The integration of a synchronously rectified boost converter, a ky converter and coupled inductor, modified ky boost converter is presented here. The coupling inductor improves the voltage gain [12]. 


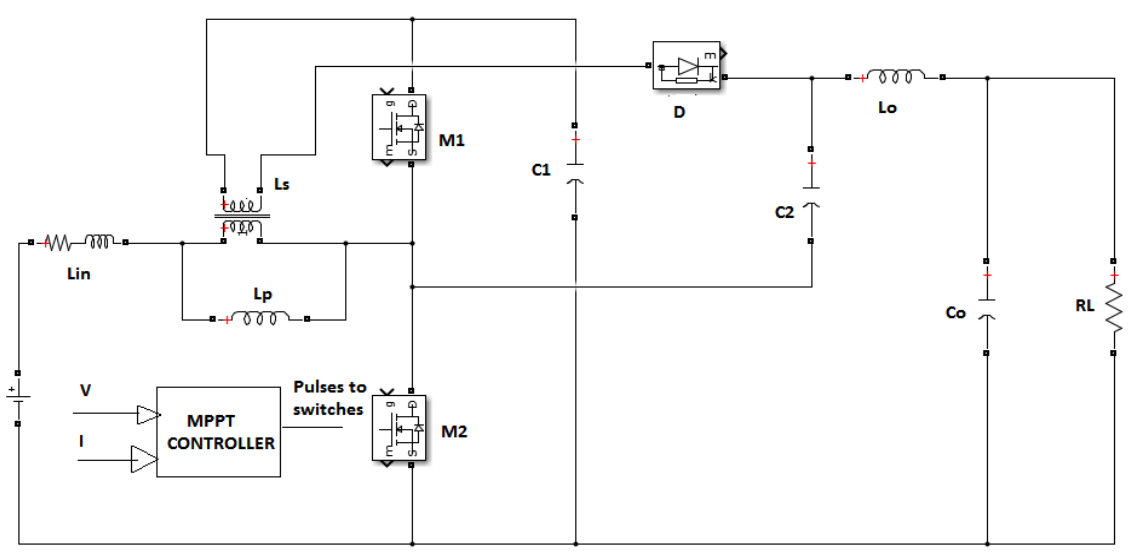

Figure 8. Circuit diagram of ky boost converter

The corresponding voltage gain can be expressed as:

$$
\frac{\text { Vout }}{\text { Vin }}=\frac{1+(\mathrm{k}-1) \mathrm{D}}{1-\mathrm{D}}
$$

$$
\text { Where } \mathrm{K}=\mathrm{Ns} / \mathrm{Np}
$$

In this paper the design parameters are The inductance and capacitance are chosen as Lin = $\mathrm{Lo}=1 \mathrm{mH}, \mathrm{C} 1=\mathrm{C} 2=200 \mathrm{uF}$ and $\mathrm{A} \mathrm{Co}=3300 \mathrm{uF}$. Vin $=270 \mathrm{~V}, \mathrm{Vo}=640 \mathrm{~V}$, the voltage conversion ratio is set at $\mathrm{K}=300 / 20=15$, frequency $100 \mathrm{kHz}$. Figure 9 shows the switching pulse applied to M1 and M2, voltage across switches and the output voltage of ky boost converter.

MPPT algorithm is developed here is $\mathrm{P} \& \mathrm{O}$ algorithm. Due to hybrid energy of wind and solar incorporates the duty cycle variation also. Sudden change in wind and solar output power the dc bus voltage is preset, results in change in output current of the ky boost converter fed to the dc bus. A current sensor senses the current through and compares it with the previous value. The duty ratio of ky boost converter hence increase or decrease. Sensing wind speed and solar insolation by adjusting the duty ratio of the ky boost converter and continuously monitoring the parameters. The Figures 9, 10 and 11 shows the corresponding output waveforms of ky converters. In all day shift the maximum power of PV module and wind extracted using Maximum Power Point Tracking (MMPT) technique. To gain a maximum power from both the renewable energy the perturb and observe method is implemented.
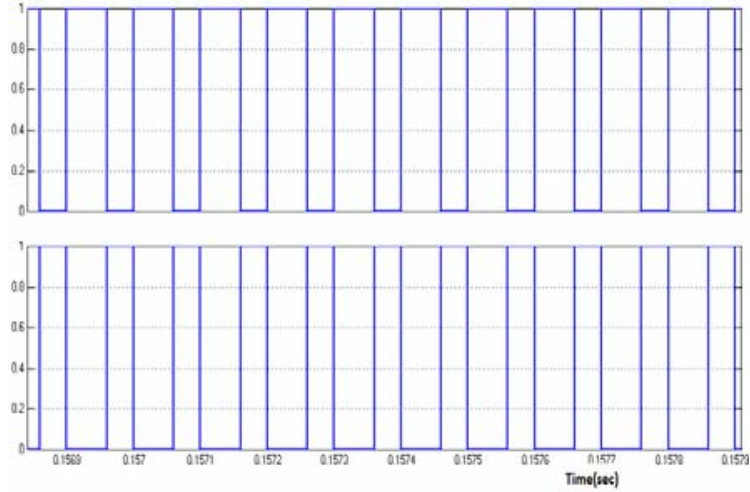

Figure 9. Switching pulse for $\mathrm{m} 1 \& \mathrm{~m} 2$

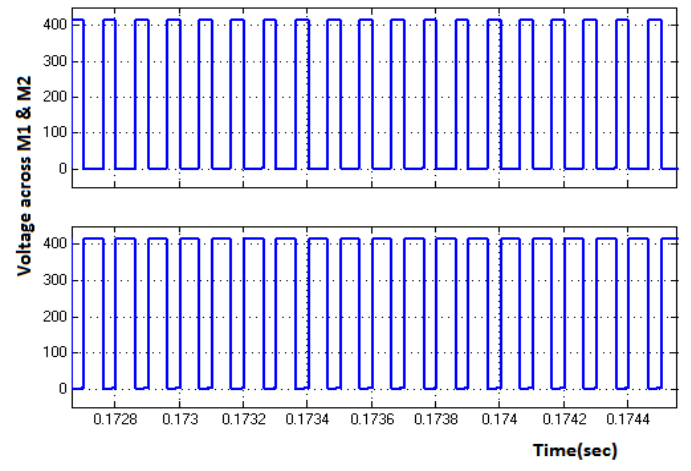

Figure 10. Voltage across $\mathrm{m} 1 \& \mathrm{~m} 2$ 
To obtain a maximum power operating voltage or current of panel is modified. If the voltage to a cell increases the power of a cell, decreases. When the power output begins to decrease the corresponding operating voltage begins to decrease. Once this situation exists, the voltage is decreased to set back to the maximum power value. This procedure persists until the maximum power point is reached. Thus, the power value fluctuates around a maximum power value until it settles.

The Figure 12 shows the flowchart of perturbation and algorithm method. This algorithm mainly focused on operating voltage and corresponding deviation of power is noted. If difference in power is positive the future perturbation should be follow the same to obtain MPP. If deviation in power is negative the perturbation should be reversed and to move reverse in direction to obtain MPP. This procedure continues until it achieves the maximum power.

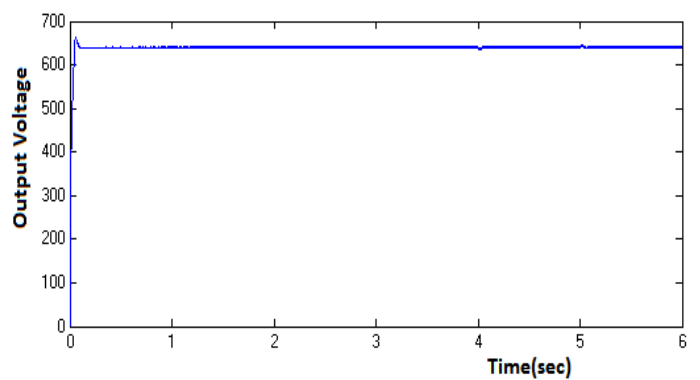

Figure 11. Output voltage.

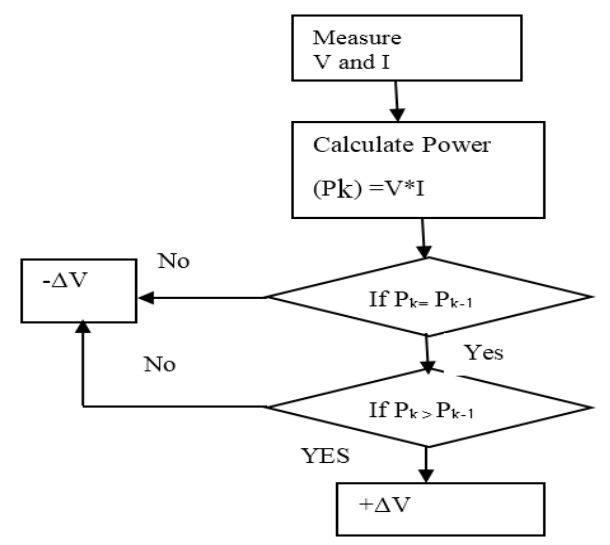

Figure 12. Flowchart of the P\&O method - MPPT algorithm

\section{WIND ENERGY}

A wind system comprises of a wind turbine, mass driven trainer, Permanent Magnet Synchronous Generator (PMSG), and AC-DC diode rectifier. Wind turbine extracts the wind's kinetic energy fed to PMSG again converted into electrical output. In this wind system using Permanent Magnet Synchronous Generator (PMSG) operates with higher efficiency and accuracy [13].

The mechanical output power $(\mathrm{P})$ of the wind turbine can be represented as

$\mathrm{P}=1 / 2 \rho \mathrm{AV} 3$

where $\mathrm{A}$ is the swept area of the turbine, $\rho$ is the density of air.

Constant or Variable speed are the two modes of Wind turbines operation. Constant speed turbine, where the rotor revolves at constant angular speed apart from the wind deviations. For the constant speed it avoids expensive power electronics inverter and converter arrangement.

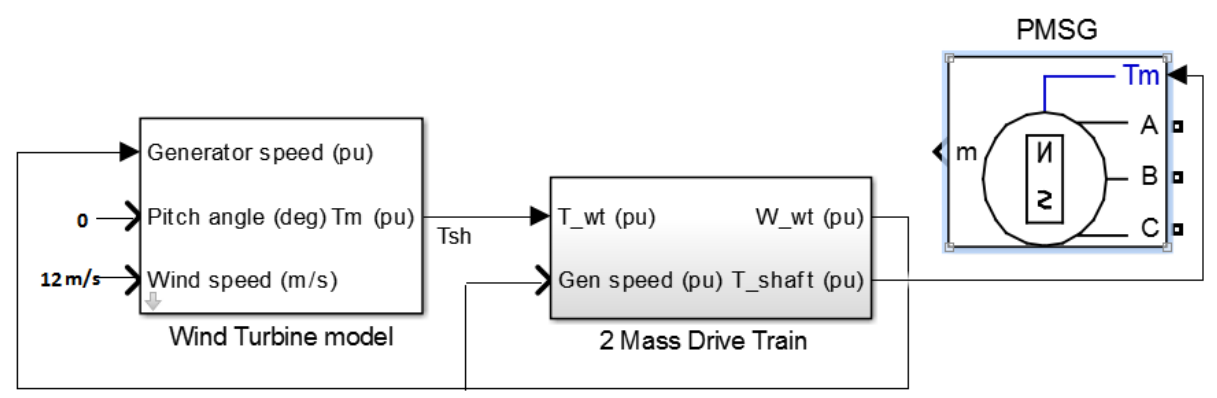

Figure 13. Connection of wind turbine to PMSG

Perfomance analysis of hybrid photovoltaic/wind energy system using ky boos converter (M. Pushpavalli) 
Maximum power at base wind velocity $=0.8$ p.u., base rotational speed $=1$ p.u. $(1500 \mathrm{rpm}), \rho=1.205$ $\mathrm{kg} / \mathrm{m} 3$, gear ratio $=1: 1, \mathrm{Cp}(\max )=0.48$ for $\beta=0 \circ$ and $\lambda=8.1$, and using these values, wind turbine has been obtained using the Wind turbine model tool in simulink. In this paper simulation is designed to work in variable speed as well as constant speed but still the output voltage remains same. Figure 13 shows wind turbine coupled to a Permanent magnet synchronous generator. The voltage, current waveforms are simulated as shown in Figure 14. Wind system specifications as shown in Table 2.

Table 2. Wind system specifications

\begin{tabular}{cc}
\hline Spesifications & Value \\
\hline Rotor inertia & $\mathrm{J}=0.01197 \mathrm{~kg}-\mathrm{m}^{2}$ \\
Stator Phase resistance & $\mathrm{Rs}=0.425 \Omega$ \\
Armature Inductance & $0.000395 \mathrm{H}$ \\
Rotational speed of the wind turbine & $\omega \mathrm{r}=140 \mathrm{rad} / \mathrm{sec}$ \\
Mechanical output power for Wind & $\mathrm{Pm}=8.5 \mathrm{KW}$ \\
Line Voltage & $392.68 \mathrm{~V}$ \\
\hline
\end{tabular}

The mechanical torque Tm produced by the wind turbine can be represented as

$$
\mathrm{Tm}=\mathrm{P} / \omega \mathrm{r}
$$

The corresponding mechanical torque $(\mathrm{Tm})$ and electrical torque $(\mathrm{Te})$ is $70 \mathrm{~N} / \mathrm{m}$. The torque waveforms represented in Figure 13. To establish the successful operation of the proposed ky boost converter and MPPT algorithm, simulation has been carried out for the given wind speed and the steady-state performance is given in Figure 15. It can be experiential from tracking MPP adjusts the duty ratio of the KY boost converter.

The wind flow is change in nature. Therefore, a wind energy system is comprised with the grid by means of an ac to dc conversion then dc to dc conversion to keep away from voltage sparkle and harmonic generation. If the wind speed changes the dc bus capacitor voltage is kept as constant as possible, achieve a decoupling between the ky boost converter and the grid side inverter. This inverter generating a Pulse width modulation voltage whose component has the same as grid frequency, and also being able to supply the real power to the grid [14].

AC power generated from PMSG is converted into DC through three phase bridge rectifier. The three phase rectifier has less total harmonic distortion and improvement of poor factor. The output of this diode rectifier connected to 270 -volt ky boost converter so that this can be integrated with solar power generation shown in Figure 16.
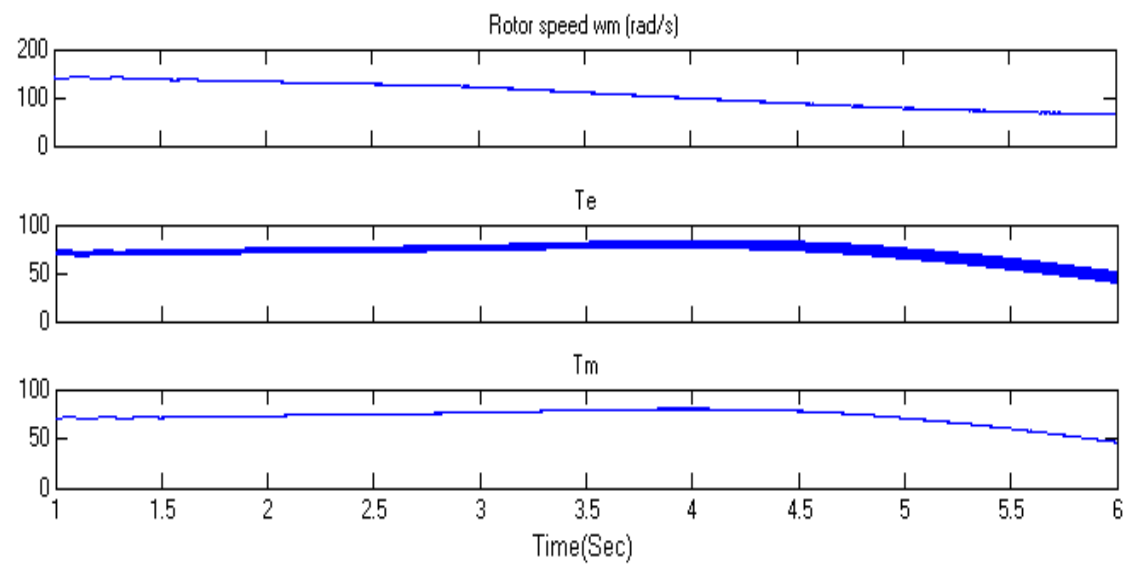

Figure 14. Torque waveforms and rotor speed 


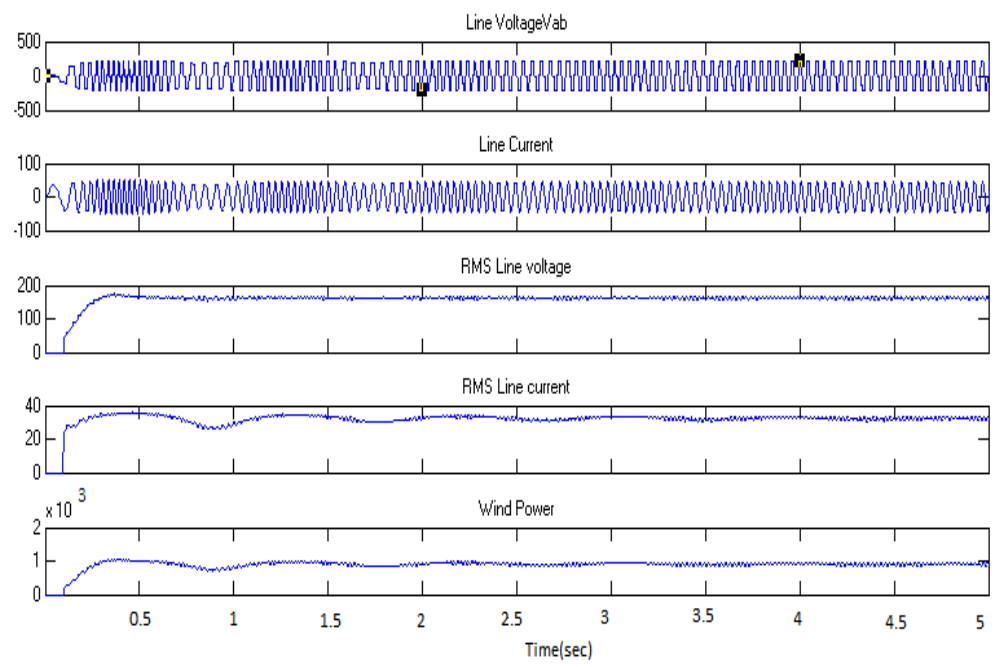

Figure 15. Output waveforms of wind system

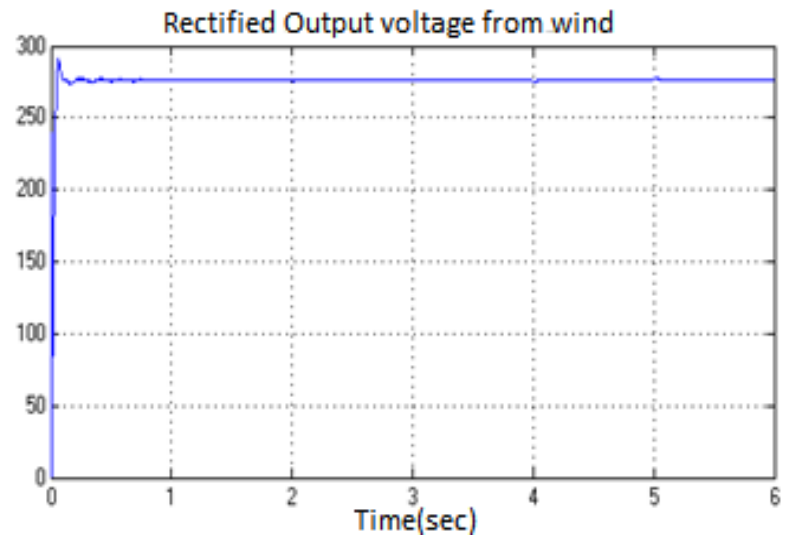

Figure 16. Rectified DC voltage from wind system

\section{BATTERY STORAGE SYSTEM}

The battery example demonstrate a $300 \mathrm{~V}, 6.5 \mathrm{Ah}$ Nickel +hydride battery connected to a dc bus as shown in Figure 17. When the State-Of-Charge (SOC) of the battery goes under $0.6(60 \%)$, recharge the battery. When the SOC goes over $60 \%$, charge the battery. To prevent battery excess charging, beyond depth of discharging, reverse current flow and to guard the life of the batteries charge controller is essential [15]-[17]. The charge controller is intended according to regulate on the battery voltage level, $320 \mathrm{~V}$ and with a current level of $6.5 \mathrm{Ah}$. The operation of charge controller is if the battery voltage reaches more than $320 \mathrm{~V}$, battery disconnected from the charging and if the voltage drops lesser than $320 \mathrm{~V}$ then it has to be connected to renewable energy. If voltage of battery in between 270 and $320 \mathrm{~V}$ then only connection between sources and battery exist. By using hysteresis relay this logic is implemented.

The charge controller unit receives the soc, battery current and dc link voltage. Depending on this parameter it generates three pwm pulses [18]-[20]. Two pulses will fed to the controller switches of the battery and another pulse is fed to the switch connected in the dc link path. Figure 18 implements the logic of charge controller algorithm. Figure 19 and Figure 20 represents the soc ,battery current and voltage. 


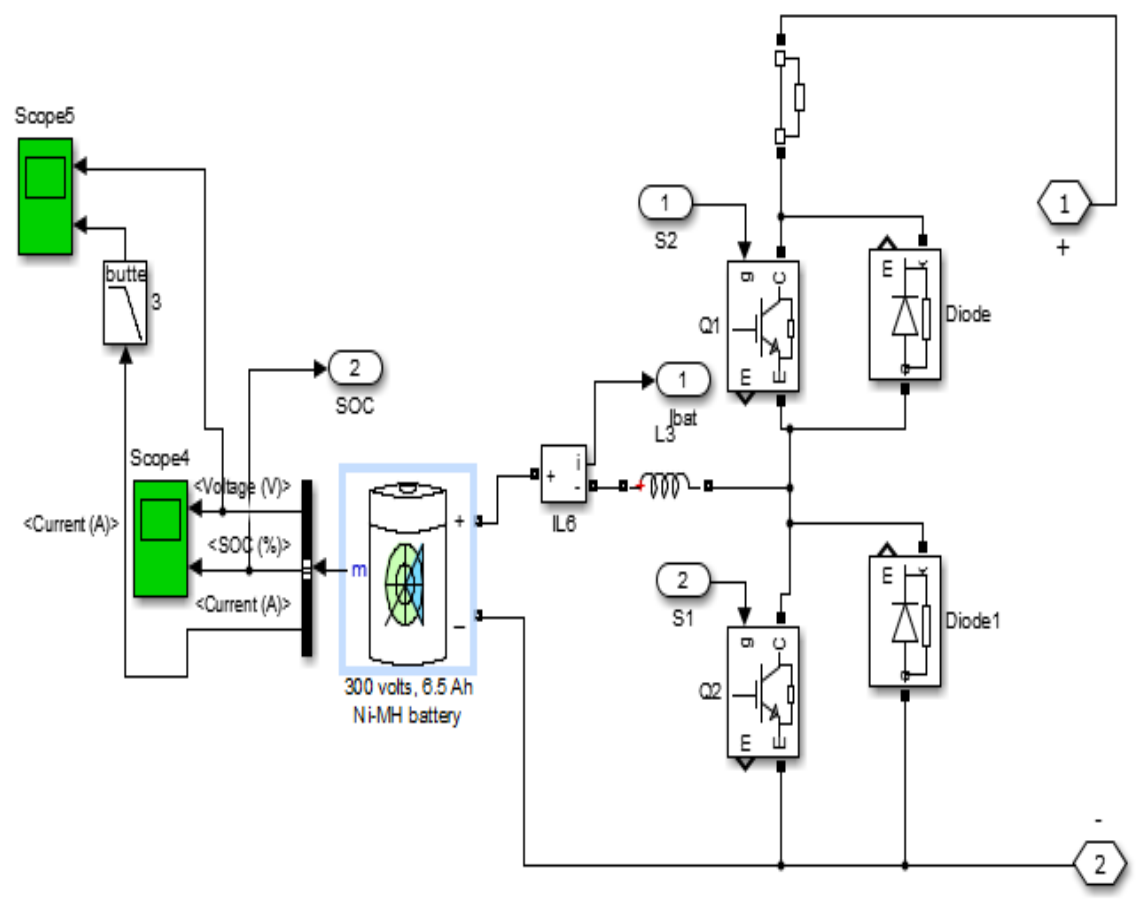

Figure 17. Simulation model of battery storage system

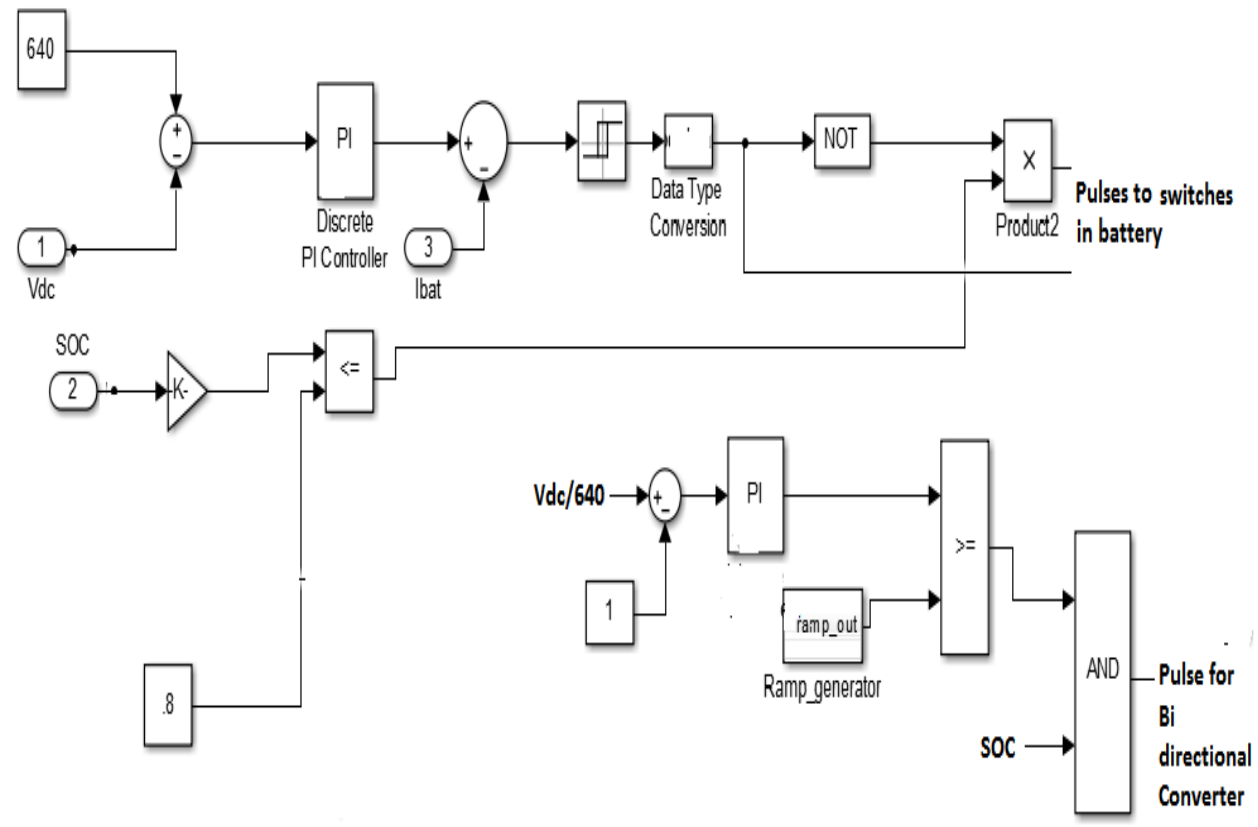

Figure 18. Simulation model of charge controller 

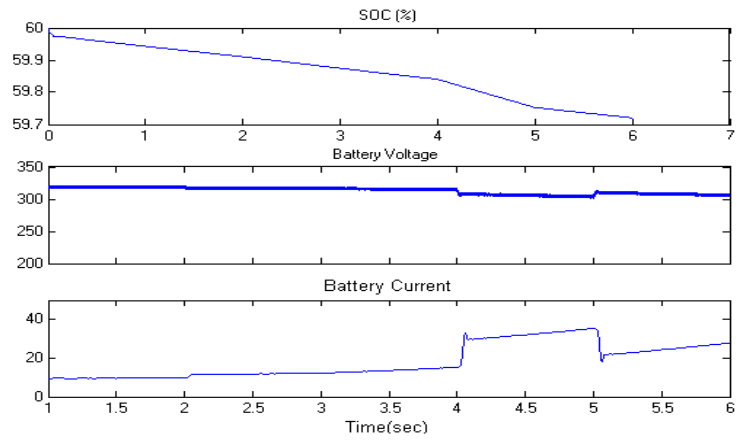

Figure 19. Battery parameter waveforms

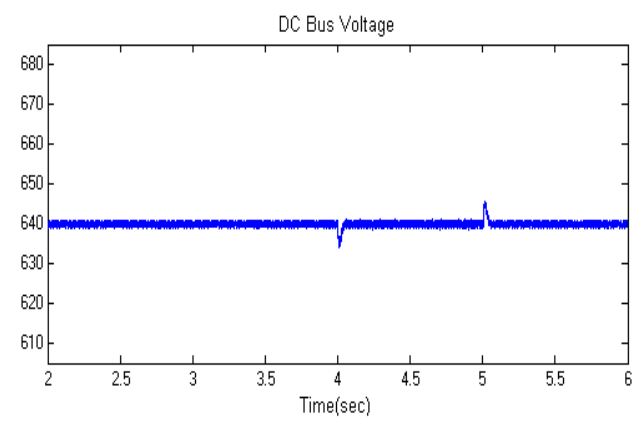

Figure 20. Constant dc bus voltage waveforms

Closed loop always necessary for disturbance in DC converters [21-22].Appropriate controller is necessary for constant output [23-24].Due to variation in input the entire system implemented in closed loop with suitable controller.

\section{GRID SYSTEM}

This section introduces grid topology and the main parameters of the investigated hybrid system. The hybrid combination minimizes the harmonic content of the voltage to some extent The converter control minimizes the grid harmonics and sends the real power in to the grid. Controlling the grid to operate in high power factor mode hence, the reactive power is reduced. The transient variation in any solar or wind energy between 4 to 5 second it incorporates the variation and settled to further. Universal bridge inverter converts dc voltage 640 volt shown in Figure 23 into three phase ac voltage. In Figure 25, the FFT analysis of the voltage is given. It is observed that the THD of the three phase voltage is $4.05 \%$, which confirms the strength of the proposed control system. Simulation model of hybrid system as shown in Figure 21. In Figure 22, waveforms of grid current and dc bus current. Powerfactor of grid system is shown in Figure 24.

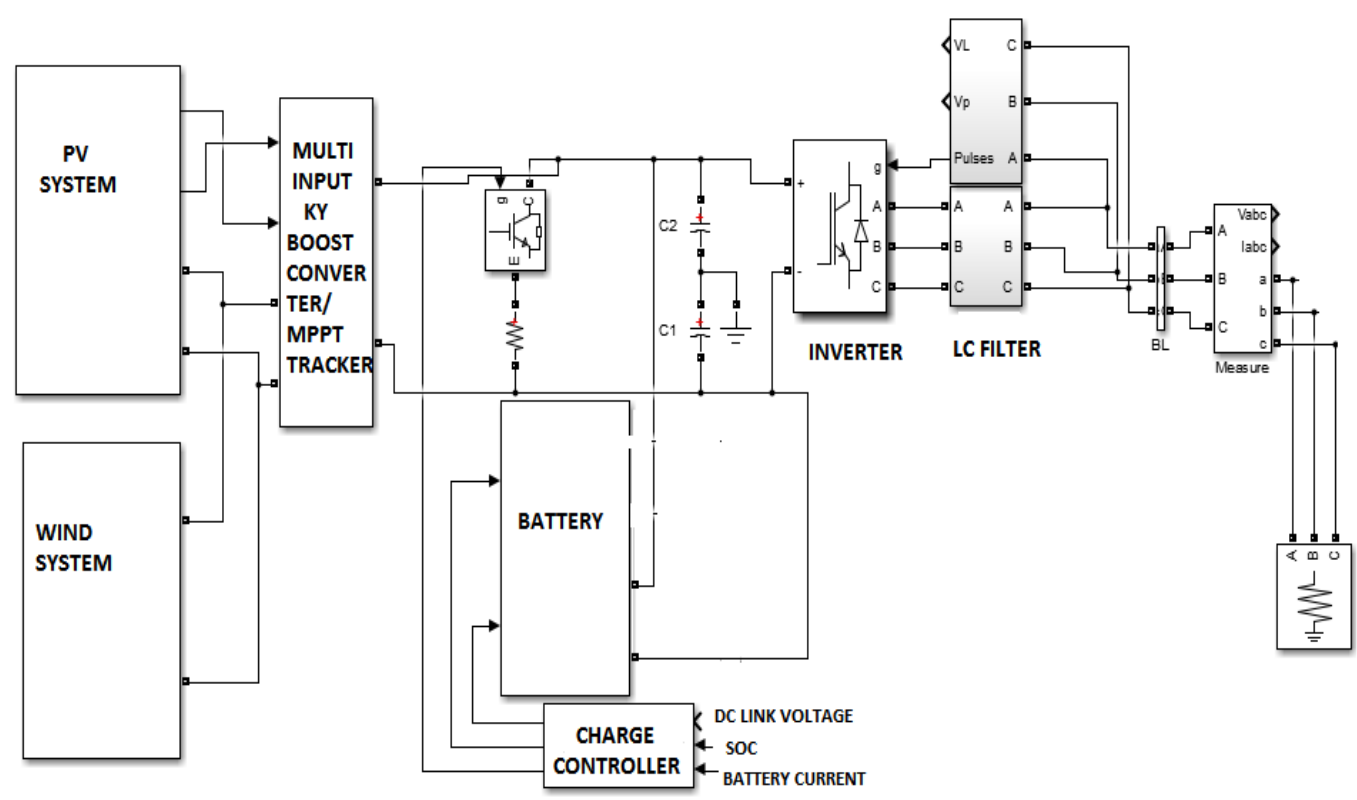

Figure 21. Simulation model of hybrid system

Perfomance analysis of hybrid photovoltaic/wind energy system using ky boos converter (M. Pushpavalli) 


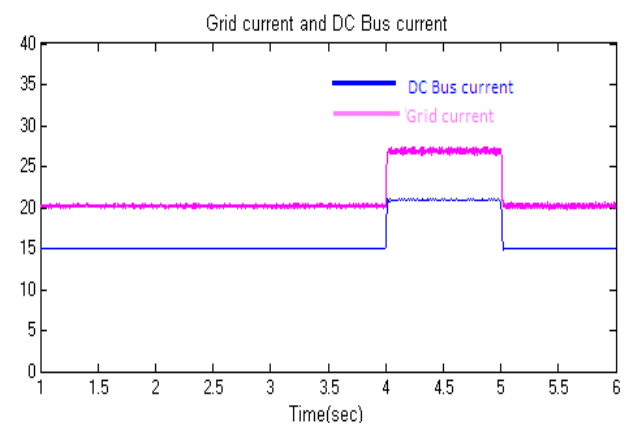

Figure 22. Waveforms of grid current and dc bus current

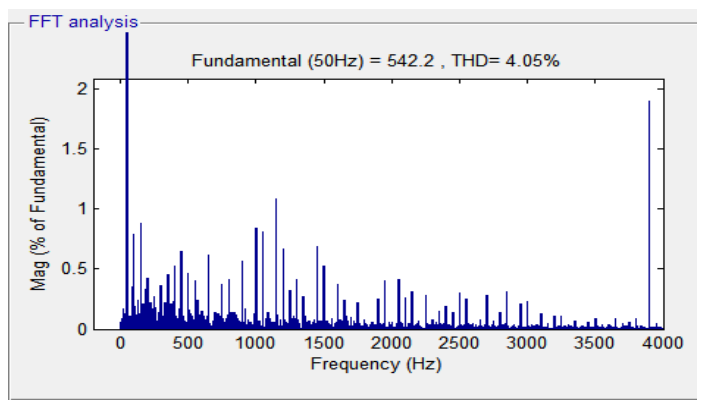

Figure 24. Powerfactor of grid system

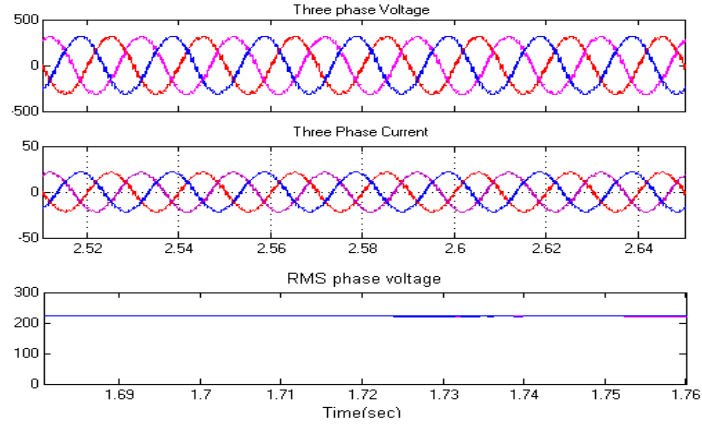

Figure 23. voltage and current waveforms of grid system

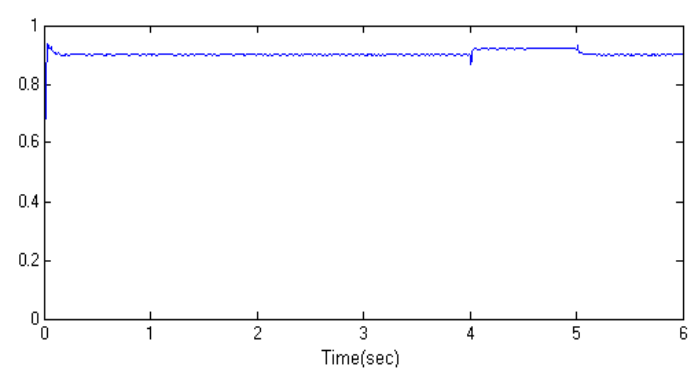

Figure 25. Fft analysis of grid voltage

\section{CONCLUSION}

This paper proposed a novel implemented multi input ky boost converter for hybrid system connected to the grid. The proposed converter is supplied by a PV array and a wind energy. In the present methods, the control parameters are dependent upon the wind, sun, storage and grid conditions and must be retained with the dynamic conditions. DC bus voltages used to manage the input for the various working mode control during various working conditions. Simulation results for different energy sources have shown the analysis of the proposed novel structure of hybrid system with desired quality.

\section{REFERENCES}

[1] Fernando Jaramillo-Lopez, Godpromesse Kenne, and Francoise Lamnabhi-Lagarrigue, "A novel online training neural network-based algorithm for wind speed estimation and adaptive control of PMSG wind turbine system for maximum power extraction”, Renewable Energy 86, pp. 38-48, 2016.

[2] R. Ramaprabha , M. Balaji, and B.L. Mathur," Maximum power point tracking of partially shaded solar PV systemusing modified Fibonacci search method with fuzzy controller", Electrical Power and Energy Systems 43, pp. 754-765, 2012.

[3] K.Y. Lau, M.F.M. Yousof, S.N.M. Arshad, M. Anwari, and A.H.M. Yatim,” Performance analysis of hybrid photovoltaic/diesel energy system under Malaysian conditions" Energy 35, pp. 3245-3255, 2010.

[4] M. H. Nehrir, C. Wang, K. Strunz, H. Aki, R. Ramakumar, J. Bing, Z. Miao, and Z. Salameh" A Review of Hybrid Renewable/Alternative Energy Systems for Electric Power Generation: Configurations, Control, and Applications", IEEE Transactions on Sustainable Energy, Vol. 2, No. 4, October 2011.

[5] Lie Xu, Senior and Dong Chen," Control and Operation of a DC Microgrid with Variable Generation and Energy Storage", IEEE Transactions on Power Delivery, Vol. 26, No. 4, October 2011.

[6] Ali Murtaza , Marcello Chiaberge , Mirko De Giuseppe , Diego Boero," A duty cycle optimization based hybrid maximum power point tracking technique for photovoltaic systems", Electrical Power and Energy Systems, 59, pp. 141-154, 2014.

[7] Sarina Adhikari, Student Member, IEEE, and Fangxing Li, Senior Member, IEEE," Coordinated V-f and P-Q Control of Solar Photovoltaic Generators With MPPT and Battery Storage in Microgrids", IEEE Transactions on Smart Grid, Vol. 5, No. 3, May 2014. 
[8] K. I. Hwu and Y. T. Yau "A KY Boost Converter", IEEE Transactions on Power Electronics, Vol. 25, No. 11, November 2010

[9] Mohammed A. Elgendy, Bashar Zahawi, Senior Member, IEEE, and David J. Atkinson,” Assessment of Perturb and Observe MPPT Algorithm Implementation Techniques for PV Pumping Applications", IEEE Transactions on Sustainable Energy, Vol. 3, No. 1, January 2012.

[10] M.Rezkallah Ab.Hamadi and A.Chandra, Fellow IEEE, Bhim Singh, Fellow IEEE, "Hybrid AC-DC Standalone System Based on PV Array and Wind Turbine", IEEE xplorer on 2014.

[11] S. H. Hosseini, Danyali, Nejabatkhah, and A.KH. Mozafari Niapoor," Multi-Input DC Boost Converter for Grid Connected Hybrid PV/FC/Battery Power System", IEEE Electrical Power \& Energy Conference, 2010.

[12] Kuo-Ing Hwu† and Wen-Zhuang Jiang," A KY Converter Integrated with a SR Boost Converter and a Coupled Inductor" Journal of Power Electronics, Vol. 17, No. 3, pp. 621-631, May 2017.

[13] V. Nayanar, N. Kumaresan, and N. Ammasai Gounden," A Single-Sensor-Based MPPT Controller for WindDriven Induction Generators Supplying DC Microgrid," IEEE Transactions on Power Electronics, Vol. 31, No. 2, February 2016.

[14] Zhe Chen, Senior Member, IEEE, Josep M. Guerrero, Senior Member, IEEE, and Frede Blaabjerg, Fellow, IEEE," A Review of the State of the Art of Power Electronics for Wind Turbines", IEEE Transactions on Power Electronics, Vol. 24, No. 8, August 2009.

[15] Simon Wenig, Freiber Rojas, Kevin Schönleber, Michael Suriyah and Thomas Leibfried," Simulation Framework for DC Grid Control and ACDC Interaction Studies Based on Modular Multilevel Converters", IEEE Transactions on Power Delivery, Vol. 31, No. 2, April 2016.

[16] Mohammed A. Elgendy, Bashar Zahawi and David J. Atkinson," Assessment of Perturb and Observe MPPT Algorithm Implementation Techniquesfor PV Pumping Applications," IEEE Transactions on Sustainable Energy, Vol. 3, No. 1, January 2012.

[17] B. Mangu, S. Akshatha, D. Suryanarayana, and B. G. Fernandes, "Grid-Connected PV-Wind-Battery-Based MultiInput Transformer-Coupled Bidirectional DC-DC Converter for Household Applications", IEEE Journal of Emerging and Selected Topics In Power Electronics, Vol. 4, No. 3, September 2016

[18] Ali Akbar Ghassami , Seyed Mohammad Sadeghzadeh, Asma Soleimani," A high performance maximum power point tracker for PV systems", Electrical Power and Energy Systems, 53, pp. 237-243, 2013.

[19] Neil S. D’Souza, Luiz A.C. Lopes, XueJun Liu," Comparative study of variable size perturbation and observation maximum power point trackers for PV systems", Electric Power Systems Research, 80, pp. 296-305, 2010.

[20] Fayez F. M. El-Sousy, Mohamed Orabi,and Hatem Godah,” Maximum Power Point Tracking Control Scheme for Grid Connected Variable Speed Wind Driven Self-Excited Induction Generator", Journal of Power Electronics, Vol. 6, No. 1, January 2006.

[21] P.Sivagami and Dr. N. M. Jothi Swaroopan," Performance Measures of Positive Output Superlift Luo Converter Using Multitudinous Controller" International Journal of Power Electronics and Drive System (IJPEDS), Vol. 9, No. 2, June 2018.

[22] P.Abirami and Merin Lizbeth George," Implementation of NN Controlled DVR for Enhancing the Power Quality by Mitigating Harmonics" International Journal of Power Electronics and Drive Systems (IJPEDS), Vol 9, No 2, pp. 738-743, 2018

[23] Kavitha, M., and V. Sivachidambaranathan. "Comparison of Different Control Techniques for Interleaved DC-DC Converter." International Journal of Power Electronics and Drive Systems Vol 9, No 2, pp. 641-647, 2018.

[24] M. L. Bharathi and D. Kirubakaran "FOPID Controlled Three Stage Interleaved Boost Converter Fed DC Motor Drive." International Journal of Power Electronics and Drive Systems (IJPEDS), Vol 8, No 4, pp. 1771-1775, 2017. 